\title{
GPS Interferometric Reflectometry measurements of ground surface elevation changes in permafrost areas in northern Canada
}

Jiahua Zhang ${ }^{1}$, Lin $\mathrm{Liu}^{1}$, Yufeng $\mathrm{Hu}^{2}$

${ }^{1}$ Earth System Science Programme, Faculty of Science, The Chinese University of Hong Kong, Hong Kong, 999077, China $5 \quad{ }^{2}$ College of Geology Engineering and Geomatics, Chang'an University, Xian, 710000, China

Correspondence to: Jiahua Zhang (zhangjiahua@link.cuhk.edu.hk)

\section{Supplementary}

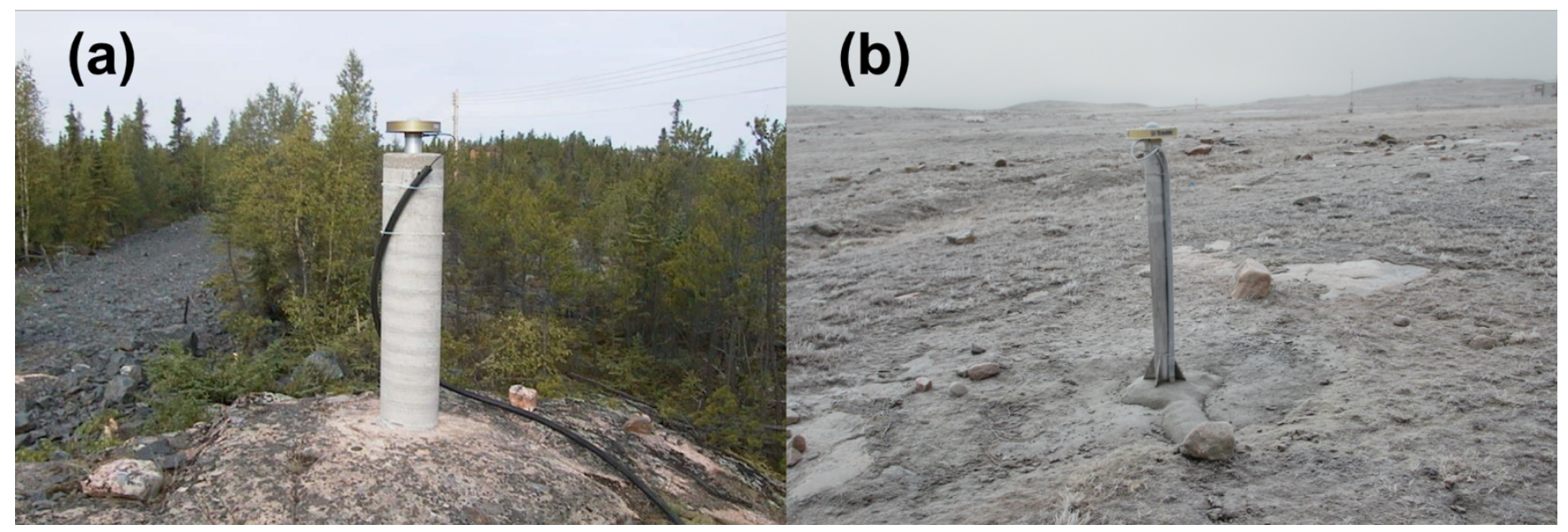

Figure S1: Ground photos of two GPS stations (a) KGLK and (b) REPL (source: https://webapp.geod.nrcan.gc.ca/geod/data-

10 donnees/cacs-scca.php?locale=en). (a) shows that KGLK is located above an undulated and inhomogeneous surface and surrounded by tall shrubs. This is a negative example and no azimuth range can be selected. (b) shows a positive example that surrounding surface of REPL is open, nearly flat, and relatively homogeneous. 


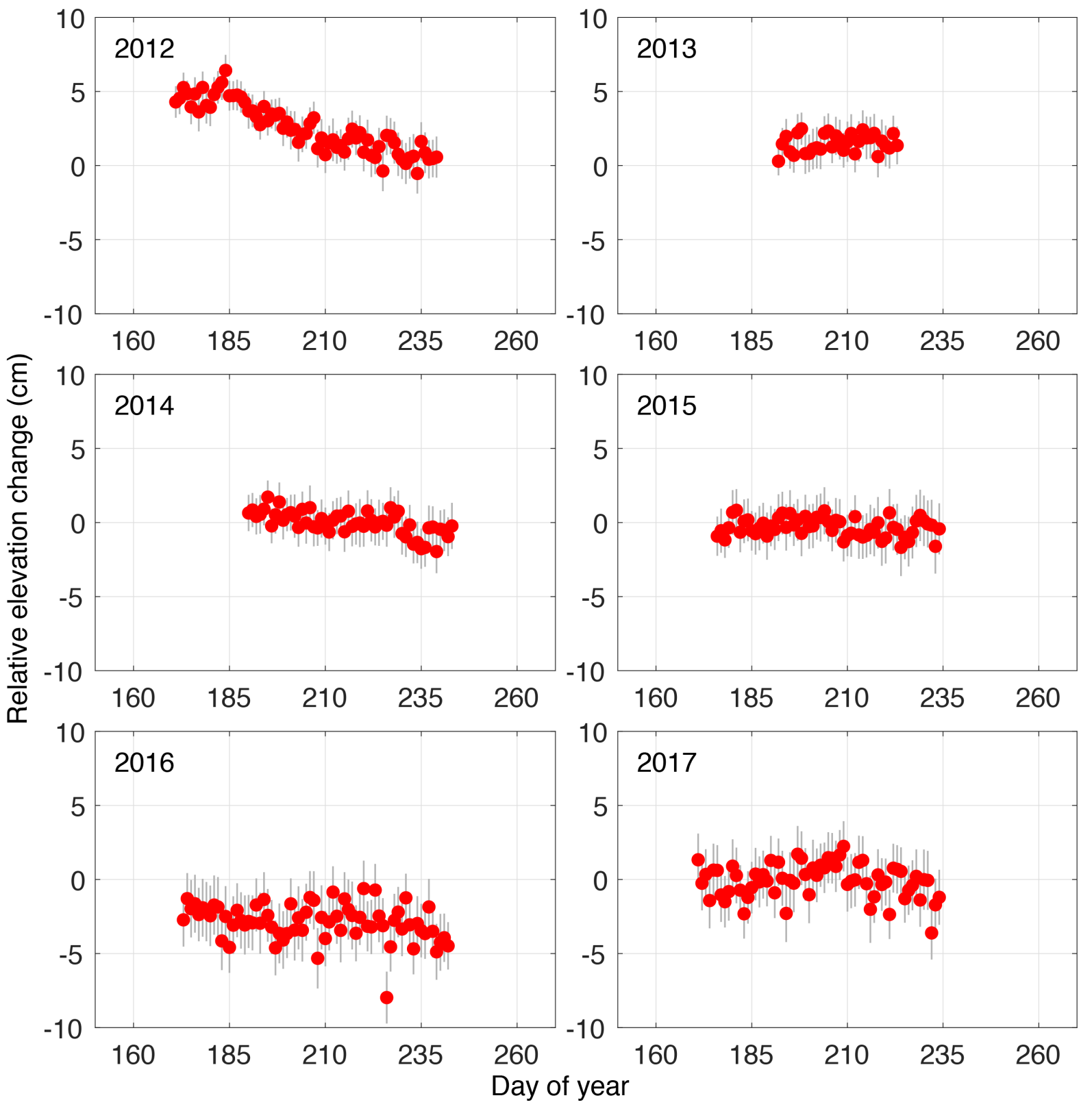

15 Figure S2: Surface elevation changes in each thaw season in Alert during 2012-2017. Red dots denote the measurements in thaw seasons. Grey error-bars denote the uncertainties. The mean value of the measurements has been removed. 


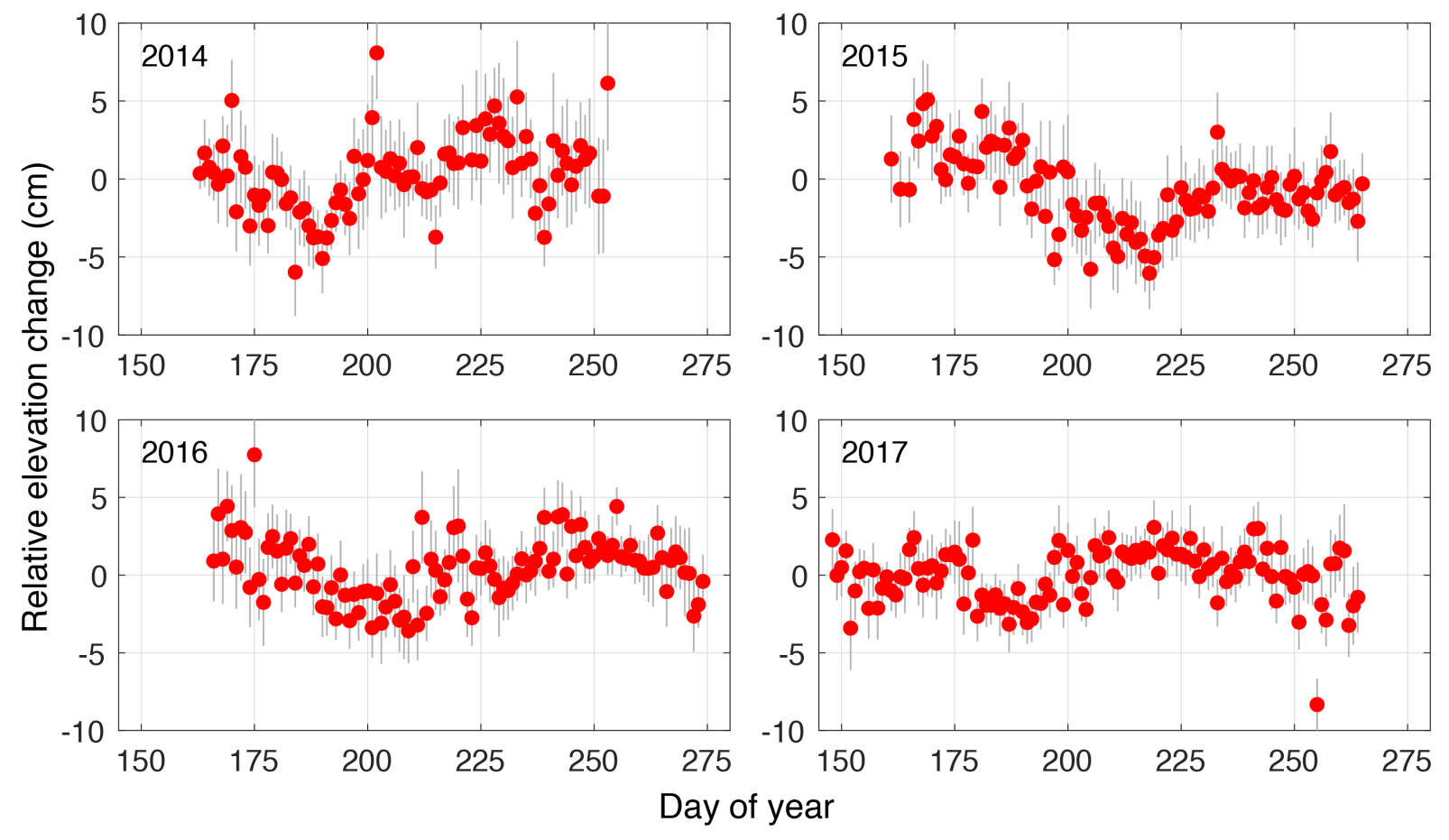

Figure S3: Similar to Fig. S2 but for Repulse Bay during 2014-2017. 

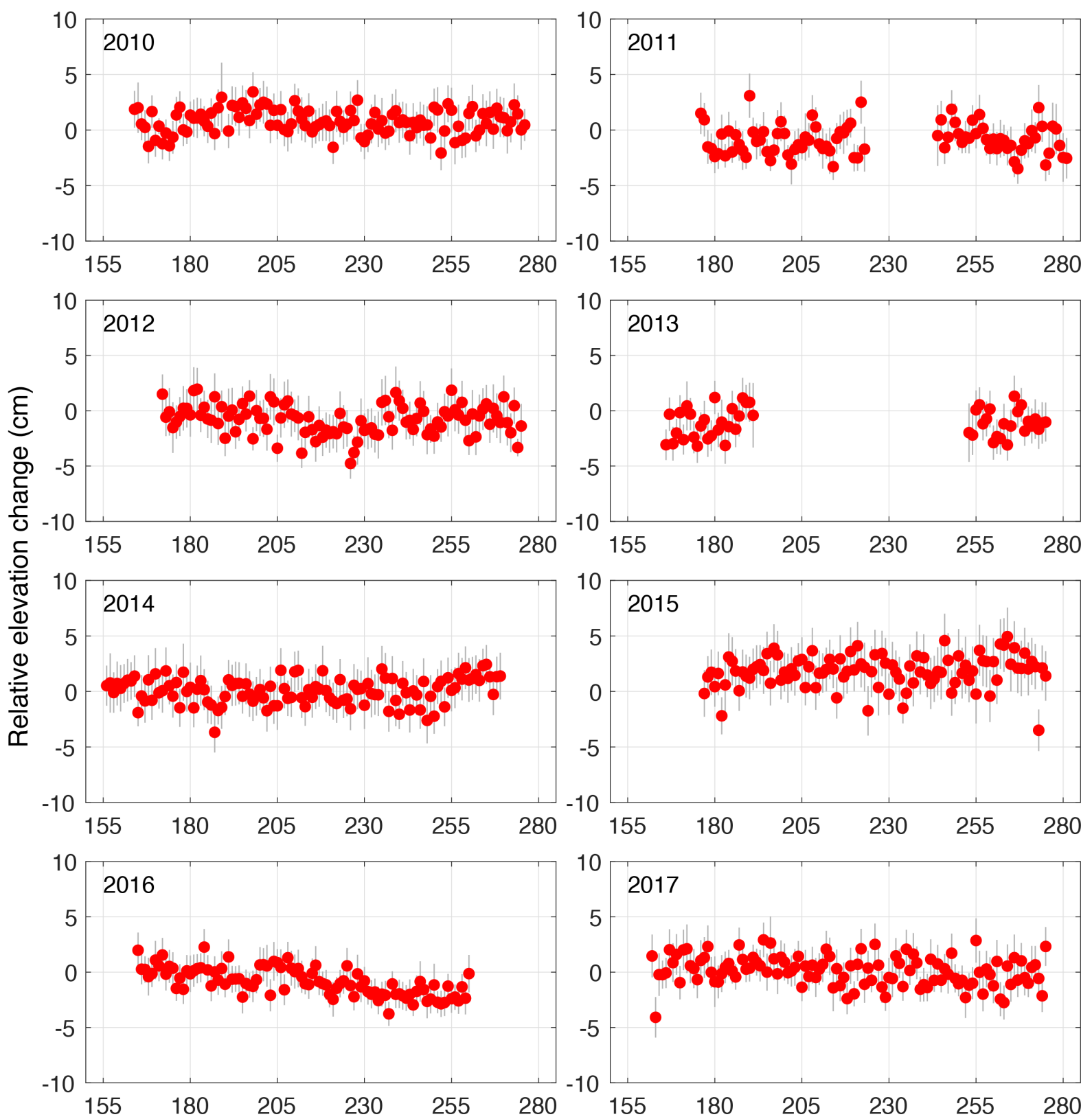

Day of year

Figure S4: Similar to Fig. S2 but for Baker Lake during 2010-2017. 

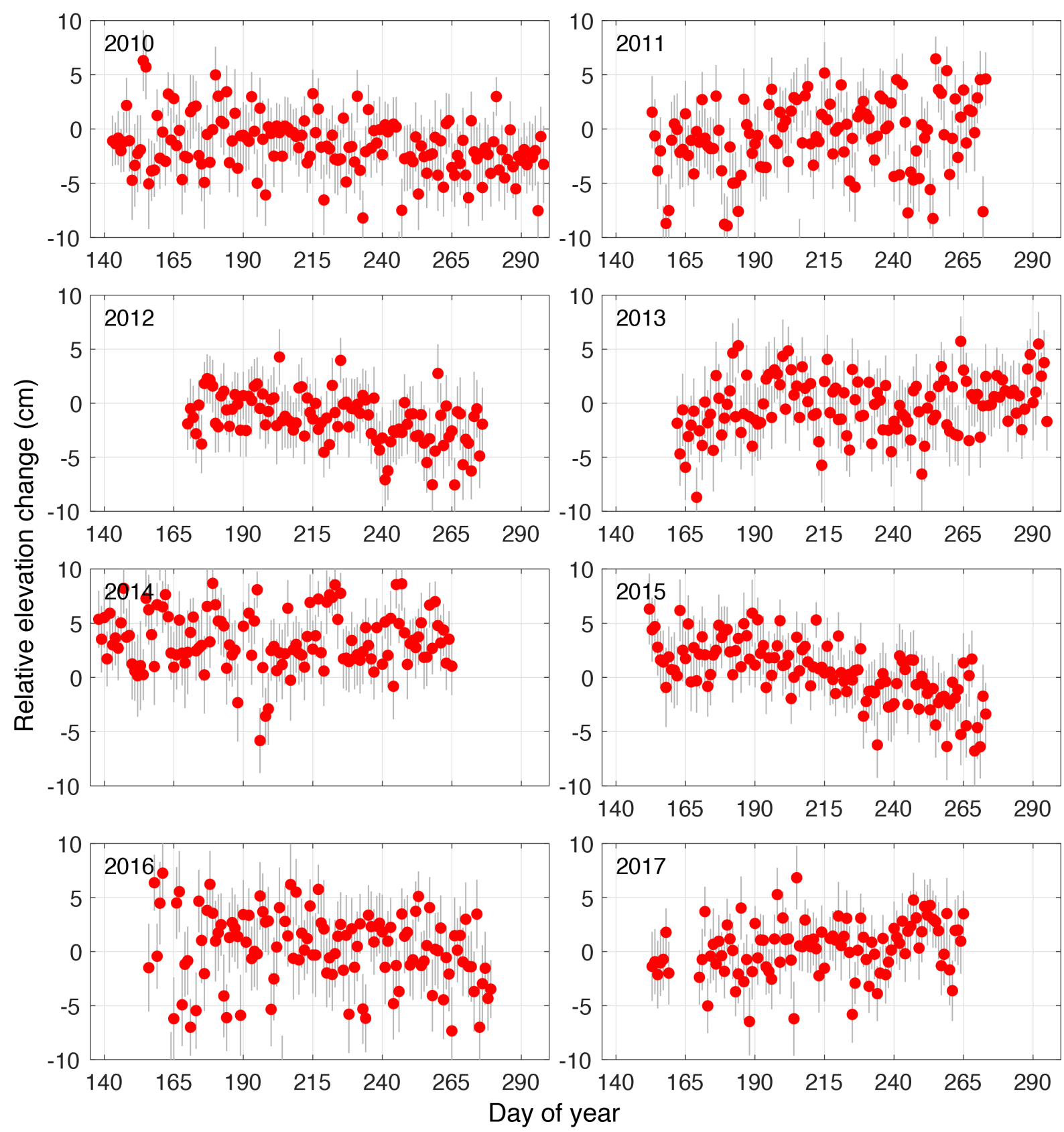

Figure S5: Similar to Fig. S2 but for Iqaluit during 2010-2017. 